\title{
Rheological Properties of Barley and Flaxseed Composites
}

\author{
George. E. Inglett ${ }^{1 *}$, Diejun Chen ${ }^{1}$, Suyong Lee $^{2}$ \\ ${ }^{1}$ USDA, Agricultural Research Service, National Center for Agricultural Utilization Research Functional Foods Research Unit, Peo- \\ ria, USA; ${ }^{2}$ Department of Food Science \& Technology and Carbohydrate Bioproduct Research Center, Sejong University, Seoul, \\ South Korea. \\ Email: *George.Inglett@ars.usda.gov
}

Received November $8^{\text {th }}, 2012$; revised December $8^{\text {th }}, 2012$; accepted December $15^{\text {th }}, 2012$

\begin{abstract}
The newly developed barley-flaxseed composites were unique because barley provides the soluble fiber $\beta$-glucan that is beneficial for improving food texture and preventing coronary heart disease along with the health benefits of omega- 3 polyunsaturated fatty acids ( $\omega-3$ PUFAs) of flaxseed. The new composites of barley with flaxseeds were prepared using prowashonupana, a barley variety containing high $\beta$-glucan content, with $10 \%, 20 \%$, and $50 \%$ flaxseed for enhancing health benefits of functional food. Besides the nutritional aspects of barley-flaxseed composites, they have improved water holding capacities, texture, and useful pasting and viscoelastic qualities measured using a Rapid Visco Analyzer (RVA) followed by an advanced rheometer. The pasting and rheological properties of the barley flour were not greatly influenced by $10 \%$ ground flaxseed replacements but showed differences at the $50 \%$ replacement level. Shear thinning properties were observed for all the composites. These functional composites could be valuable and applicable for developing new functional food products with health benefits of decreasing heart problems, diabetes, and obesity along with providing desirable texture.
\end{abstract}

Keywords: Flaxseed; Barley; Omega-3; Polyunsaturated Fatty Acids; B-Glucan; Pasting Properties; Rheological Properties

\section{Introduction}

Prowashonupana barley (Hordeum vulgare) was used for blending with flaxseed since it has been an important grain for centuries [1]. Most barley varieties provide vitamins, trace minerals, dietary fiber and bioactive compounds $[2,3]$. Prowashonupana is a very special waxy type of barley used exclusively for food. It has a shrunken endosperm with very thick cell walls and higher $\beta$-glucan content than any of the other barley varieties $[4,5]$. The carbohydrate distribution in prowa-shonupana barley is at least $30 \%$ dietary fiber and $<30 \%$ starch which is $2-3$ times the amount of fiber and half the amount of starch compared with other common cereal grains. Barley grains are generally rich in $\beta$-glucan that provides an excellent source of soluble dietary fiber for attenuating blood glucose, and reducing low-density lipoprotein cholesterols (LDL) [6]. Barley grains also contain $\beta$-glucan which has beneficial health effects on coronary heart disease prevention by the reduction of serum cholesterol and postprandial serum glucose levels [7]. Prowashonupana barley has an exceptionally high $\beta$-glucan of $15 \%$ with approximately half of the dietary fiber as $\beta$-glucan [5]. The benefits of dietary fiber on

${ }^{*}$ Corresponding author. inflammatory bowel disease may be related to the fermentative production of butyrate in the colon which appears to decrease the inflammatory response [8]. Products containing $\beta$-glucan have numerous functional food applications to reduce fat content and calories in a variety of foods [9]; control the rheology and texture of food products [10]; modify starch gelatinization and retrogradation [11,12]; and also provide freezing/thawing stability [13]. In addtion, barley is gaining renewed interest as an ingredient for production of functional foods due to its high contents of bioactive compounds such as glucans, tocopherols and tocotrienols [14]. Moreover, there are many classes of phenolic compounds in barley, such as benzoic and cinnamic acid derivatives, proanthocyanidins, quinones, flavonols, chalcones, flavones, flavanones and amino phenolic compounds [3,15,16,17].

Flaxseed (Linum usitatissimum L.) is a well known plant source for $\omega$-3 PUFAs-rich oils that have a positive effect on human health. The $\omega-3$ polyunsaturated fatty acids ( $\omega-3$ PUFAs) have received increased attention because the consumption of $\omega-3$ PUFAs has been linked to reducing risk of coronary heart disease (CHD) $[18,19]$. Flaxseed oil have been used to help reduce total blood cholesterol and low-density lipoprotein (LDL) choles- 
terol levels and it has being increasingly recognized for reducing the risk of cardiovascular diseases [20]. The Food and Drug Administration (FDA) has approved a health claim for reduced risk of CHD for foods containing $\omega-3$ PUFAs, mainly eicosapentaenoic (EPA, 20:5n3) and docosahexaenoic (DHA, 22:6n3) [21]. Also, flaxseed is rich in fiber, and contains natural antioxidants such as phenolic glycoside- $\mathrm{Q}$ and $\mathrm{K}$, chlorogenic acid, caffeic acid, quercetin and kaempferol which may protect consumers against some cardiovascular diseases and types of cancer; as well as supplying vitamins and minerals [22]. In addition, mucilaginous constituents of flaxseed have a considerable potential for use as a food gum $[23,24]$. Previous studies have revealed that flaxseed mucilage consists of two types of polysaccharides: a neutral arabinoxylan and an acidic pectic-like material [25]. Recently, Wannerberger et al. (1991) reported that mucilages extracted from different flaxseed cultivars exhibit different rheological properties[26]. Experiments have shown that extraction conditions also have substantial impact on the yield, chemical composition, and rheological properties of flaxseed gum [27].

Functional food products fortified with $\omega-3$ PUFAs are in increasing demand because of their demonstrated health benefits. Also, there is a urgent need for improving functional performance of flaxseed since its viscosity and cohesion are low for food applications. The barley flour was used to blend with flaxseed in this study to produce unique composites containing $\beta$-glucan in combination with flaxseed seeds containing its distinctive omega-3 oils. The barley flour component appears to be helpful in absorbing oil and improving physical properties such as water holding capacity. Furthermore, the rheological properties of flaxseed combined with barley provided new and useful information on the interesting composites. Thus, the purpose of our study was conducted to explore the pasting and rheological characteristics of dry blended barley flour with ground flaxseed that could be valuable for processing and developing potential new functional food products having desirable texture and health benefits.

\section{Materials and Methods}

\subsection{Preparation of Barley-Flaxseed Composites}

Prowashonupana barley flour was provided by Conagra Mills (Omaha, NE, USA). Golden flaxseed was supplied by Bob's Red Mill (Milwaukie, OR, USA). Flaxseeds were ground for 1 min using an IKA M20 mill (IKA ${ }^{\circledR}$ Works, Inc. Wilmington, NC USA). Ground flaxseeds were mixed with corresponding amount of barley flour using a N-50 Hobart mixer (Hobart Canada INC., Ontario, Canada) for $1 \mathrm{~min}$. The mixtures were ground again with an IKA M20 mill for another 40 seconds for additional mixing to obtain the desired composites.

\subsection{Water-Holding Capacity Determination}

The water-holding capacities of samples were determined according to procedure of Ade-Omowaye (2003) with modifications [28]. Samples (2 g) were mixed with $25 \mathrm{~g}$ of deionized water and vigorously mixed using a vortex to make a suspension, then held for $2 \mathrm{~h}$, followed by centrifugation at $1590 \mathrm{~g}$ for $15 \mathrm{~min}$. The supernatant was decanted and weight of residue was measured. Each treatment was replicated twice. Water-holding capacity was calculated by the following equation:

Water holding capacity $(\%)=[($ sample weight after centrifugation - dry sample weight $) /$ dry sample weight $] \times 100$

\subsection{Pasting Property Measurement}

The pasting properties of samples were measured using a Rapid Visco Analyzer (RVA-4, Perten Scientific, Springfield, IL). Samples ( $2.24 \mathrm{~g}$ d.b.) were made up to a total weight of $28 \mathrm{~g}$ with distilled water in a RVA canister ( $8 \%$ solids, $\mathrm{w} / \mathrm{w})$. The viscosity of the suspensions was monitored during the following heating and cooling stages. Suspensions were equilibrated at $50^{\circ} \mathrm{C}$ for $1 \mathrm{~min}$, heated to $95^{\circ} \mathrm{C}$ at a rate of $6.0^{\circ} \mathrm{C} / \mathrm{min}$, maintained at $95^{\circ} \mathrm{C}$ for $5 \mathrm{~min}$, and cooled to $50^{\circ} \mathrm{C}$ at rate of $6.0^{\circ} \mathrm{C} / \mathrm{min}$, and held at $50^{\circ} \mathrm{C}$ for $2 \mathrm{~min}$. For all test measurements, a constant paddle rotating speed (160 rpm) was used throughout the entire analysis except for $920 \mathrm{rpm}$ in the first $10 \mathrm{~s}$ to disperse samples. Each sample was analyzed in duplicate. The results were expressed in Rapid Visco Analyser units (RVU, $1 \mathrm{RVU}=12$ centipoises).

\subsection{Rheological Measurement}

After the RVA measurements, the rheological properties of the samples were analyzed on a rheometer (AR 2000, TA Instruments, New Castle, DE) using a $4 \mathrm{~cm}$ diameter parallel stainless plate. The plate edge was sealed with a thin layer of mineral oil (Sigma Chemical Co., St Louis, $\mathrm{MO})$ to prevent dehydration during the test. All rheological measurements were carried out at $25^{\circ} \mathrm{C}$ using a circulation system within $\pm 0.1^{\circ} \mathrm{C}$. A strain sweep experiment was conducted initially to determine the limits of linear viscoelasticity; then a frequency sweep test was carried out to obtain storage modulus $\left(\mathrm{G}^{\prime}\right)$ and loss modulus $\left(\mathrm{G}^{\prime \prime}\right)$ at frequencies ranging from 0.01 to $10 \mathrm{rad} / \mathrm{s}$. A strain of $0.1 \%$, which was within the linear viscoelastic range, was used for the dynamic experiments. Also, the steady shear sweep measurements applied varying steady 
shear deformation on the tested materials at magnitudes based on user-specified shear rates (1 to $100 \mathrm{~s}^{-1}$ ).

\subsection{Statistical Analysis}

All measurements for samples were performed in duplicate. Data were analyzed using SAS software using analysis of variance with Tukey's multiple comparison adjustment to determine significant differences $(P<0.05)$ between treatments [29].

\section{Results and Discussion}

\subsection{Water-Holding Capacity}

The water-holding capacities of the ground flaxseeds and its dry blended composites are shown in Figure 1. The water-holding capacity of ground seeds (434\%) was almost twice that of barley flour (227\%). The water-holding capacities for flax-barley composites were increased with increasing ground flaxseeds contents in the composites. However, there was no significant increase between barley, barley-flaxseed 9:1, and 4:1 $(P>0.05)$. A significant increase in water-holding capacity was observed for barley-flaxseed composite 1:1 (352\%) compared with that of barley alone $(227 \%)$. The water-holding capacity of barley-flaxseed (1:1) in this study was almost the average of the water-holding capacity of starting materials, indicating no significant interaction in these composites. Barley-flaxseed composites with increased water capacity could be widely used for their thickening and gelling properties, syneresis control, and emulsion stabilization in food industries.

\subsection{RVA Pasting Properties}

The pasting curves of the starting materials and their composites were obtained by RVA expressed as RVU units ( 1 RVU $=12$ centipoises) (Figure 2). Barley and it composites showed higher final viscosities than ground flaxseeds alone. The pasting curve of flaxseed showed a low pasting viscosity with a flat curve. The final viscosity of barley-flaxseed composite 9:1 was similar to that of barley. However, the final peak viscosity at the end of test was distinctly reduced with increasing levels of ground flaxseed. The final viscosity of barley-flaxseed composite 1:1 was lower than that of barley and other composites. It may be due to the low viscosity contributed by the ground flaxseeds. No dramatic breakdowns (peak viscosity minus the lowest point of viscosity after peak) were observed for all composites in this study. It suggests that the barley-flaxseed composites exhibited greater structural stability under heat and shear. It may be due to that uncooked $\beta$-glucan in the barley resulted in an entanglement of molecules immediately after cooking and during cooling indicated the formation of a matrix with greater stability under heat and shear.

In general, all the composites had higher viscosities than ground flaxseeds alone, and related to flaxseed percentages in the composites. This study demonstrated that the pasting quality of barley was slightly affected by the replacements with $10 \%$ of flaxseed. The $50 \%$ replacement of ground of flaxseeds had lower pasting viscosities than barley alone. The RVA data provided useful information for food processing and product development. Blends having low viscosity may be suitable for the products such as nutritional bars and cookies. Improvement in the textural properties of food using $\beta$-glucan hydrocolloids has been reported [30]. Composites with high initial paste viscosity suggest that their uses in food formulations that require little heat during processing

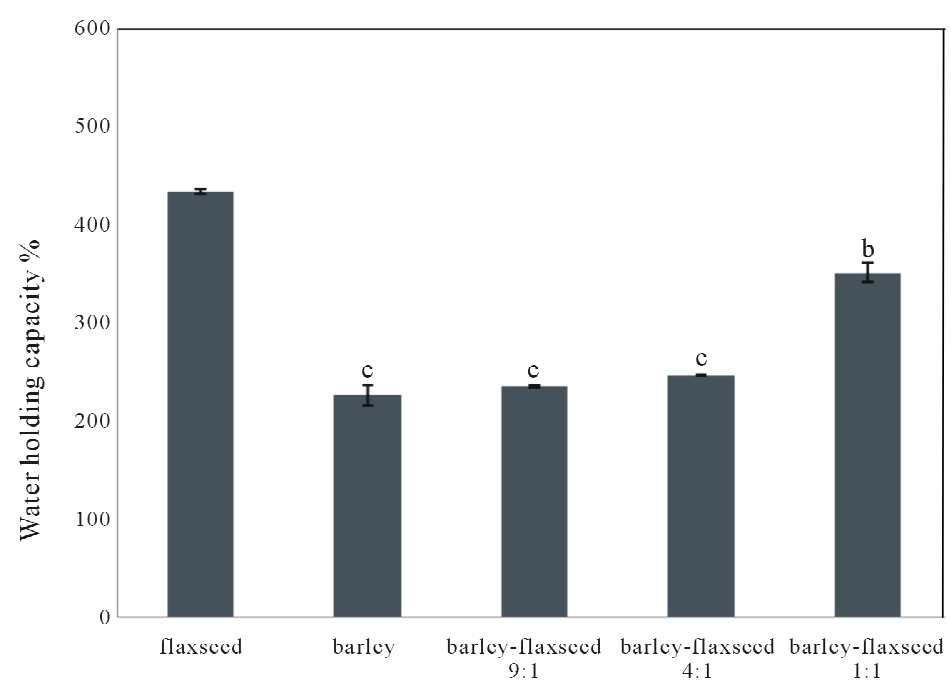

Figure 1. Water-holding capacity of flaxseed and its composites with barley; Bar labeled with different letters are significantly different $(P<0.05)$. 


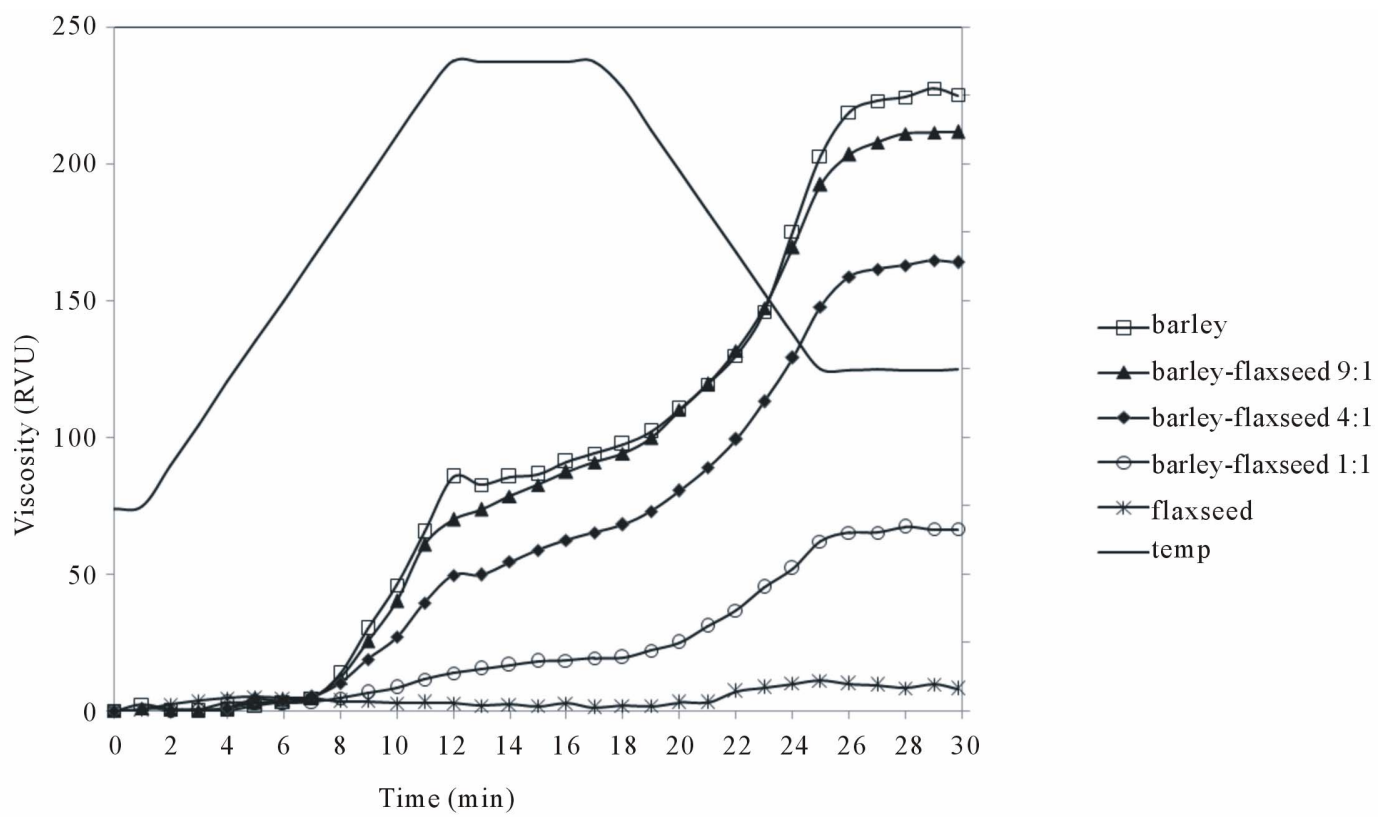

Figure 2. Rapid visco-analyser pasting curve of barley and its composites with flaxseed.

such as beverages. Also, Composites with high viscosities could be used for products such as breads for increased texture quality along with health benefits.

\subsection{Rheological Properties}

The G', an elastic (storage) moduli, represents the nondissipative component of the mechanical properties of a material and reflects its elastic characteristics. On the other hand, the viscous (loss) modulus (G") characterizes the dissipative part of the mechanical properties and represents the viscous flow of the material. The $G^{\prime}$ and $\mathrm{G}^{\prime \prime}$ moduli against frequency for ground flaxseeds and barley-flaxseed composites were displayed in Figure 3. Both G' and G" moduli of all barley-flaxseed composites were increased with increasing frequencies, showing greater frequency-dependent properties than flaxseed. Also, elastic modulus $G^{\prime}$ was greater than viscous $G^{\prime \prime}$ throughout the frequency range for flaxseed and barleyflaxseed composites at different levels, indicating more solid-like behaviors. It indicated that the property of these materials could be classified rheologically as elastic gels [31]. The highest values of storage ( $\left.\mathrm{G}^{\prime}\right)$ and loss $\left(\mathrm{G}^{\prime \prime}\right)$ moduli, and also a large difference between $G^{\prime}$ and $G^{\prime \prime}$ were observed for ground flaxseed. It suggested that that the ground flaxseeds contributed to a less viscous property but a more elastic property $[31,32]$.

The changes of $\mathrm{G}^{\prime}$ and $\mathrm{G}^{\prime \prime}$ of barley-flax composites with $10 \%$ or $20 \%$ flaxseed were not great compared with barley flour. It demonstrated that the rheological properties of the barley-flaxseed commposites were not affected greatly by $10 \%$ or $20 \%$ flaxseed replacement. Therefore replacement by $10 \%$ or $20 \%$ flaxseed from barley may not appreciably change the rheological properties of barley. A noticeable change was observed for the $50 \%$ flaxseed replacement. The $50 \%$ of flaxseed composite showed considerable different rheological properties compared to ground flaxseed.

Furthermore, these rheological patterns of the flaxseed composites were clearly confirmed by the $\tan \delta$ values (Figure 4). The values of $\tan \delta$ represents the ratio of energy lost to the amount of energy stored (loss modulus $\mathrm{G}^{\prime \prime} /$ storage modulus $\mathrm{G}^{\prime}$ ) during a test cycle. The phase shift $\delta$ is defined by $\delta=\tan ^{-1}\left(\mathrm{G}^{\prime \prime} / \mathrm{G}^{\prime}\right)$, which indicates whether a material is solid $\left(\delta=0^{\circ}\right)$, liquid $\left(\delta=90^{\circ}\right)$, or between $\left(0^{\circ}<\delta<90^{\circ}\right)$. Therefore, the values of $\tan \delta$ are from zero to infinity; and $\tan \delta=1$ means $\mathrm{G}^{\prime}=\mathrm{G}^{\prime \prime}, \tan \delta$ $<1$ represents $\mathrm{G}^{\prime}>\mathrm{G}^{\prime \prime}$, and $\tan \delta>1$ indicates $\mathrm{G}^{\prime}<\mathrm{G}^{\prime \prime}$. Thus, $\tan \delta$ was used to indicate the strong relationship between the viscous behavior and the degree of casein hydrolysis [33]. In contrast to flaxseeds, the decreased $\tan \delta$ trend was observed for barley and its composites, showing a dominant elastic behavior (Figure 4). Perhaps this result could be attributed to various interactions of the barley components. This enhanced elastic feature provides shape retention properties during handling and cooking.

The flow curves of apparent viscosity of the pastes vs. shear rate were illustrated in Figure 5. Also, each flow curve was characterized by the power model equation (Table 1). In the power law $\left(\tau=K(\gamma)^{n}, K\right.$ and $n$ are the consistency index and flow behavior index, respectively. The flow curves of barley-flaxseed composites were suitably fitted to the power model $(\mathrm{R}>0.99)$ to the experimental data in Table 1. All of the samples exhibited 


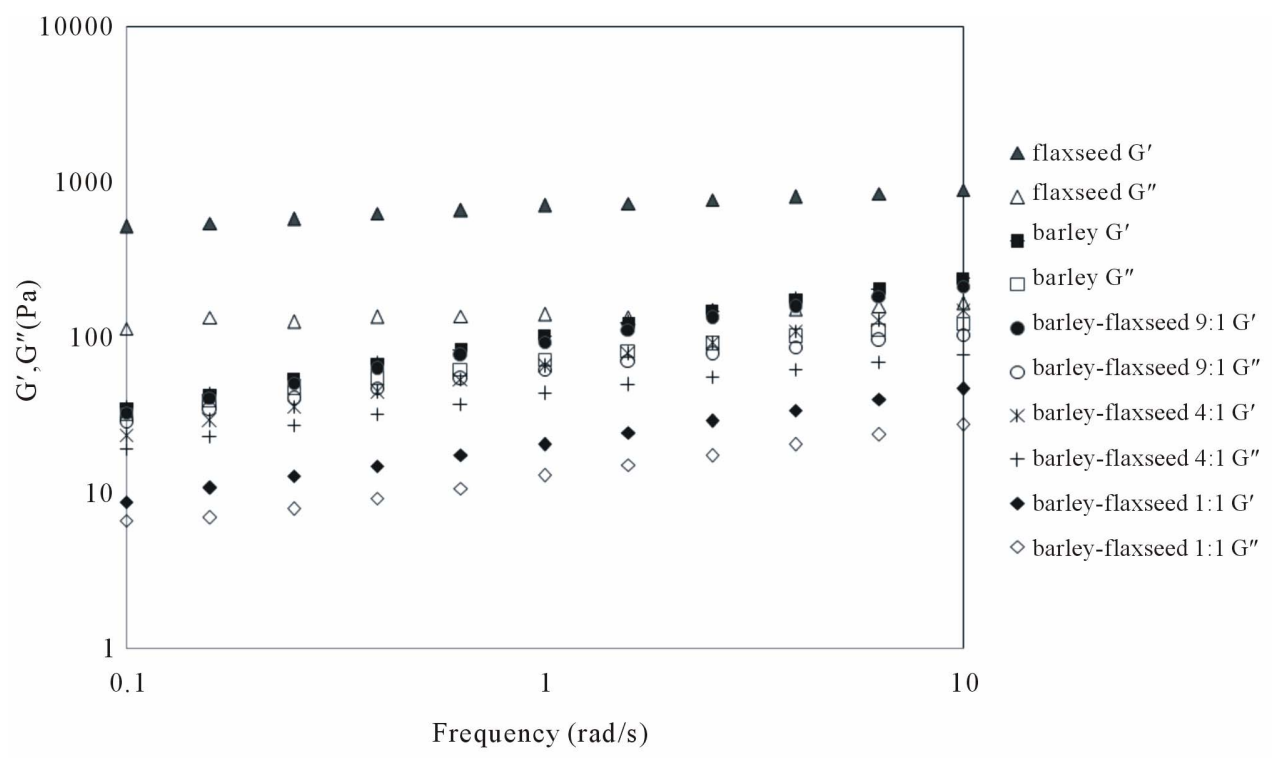

Figure 3. Dynamic viscoelastic properties of barley and its composites with flaxseed at $25^{\circ} \mathrm{C}$.

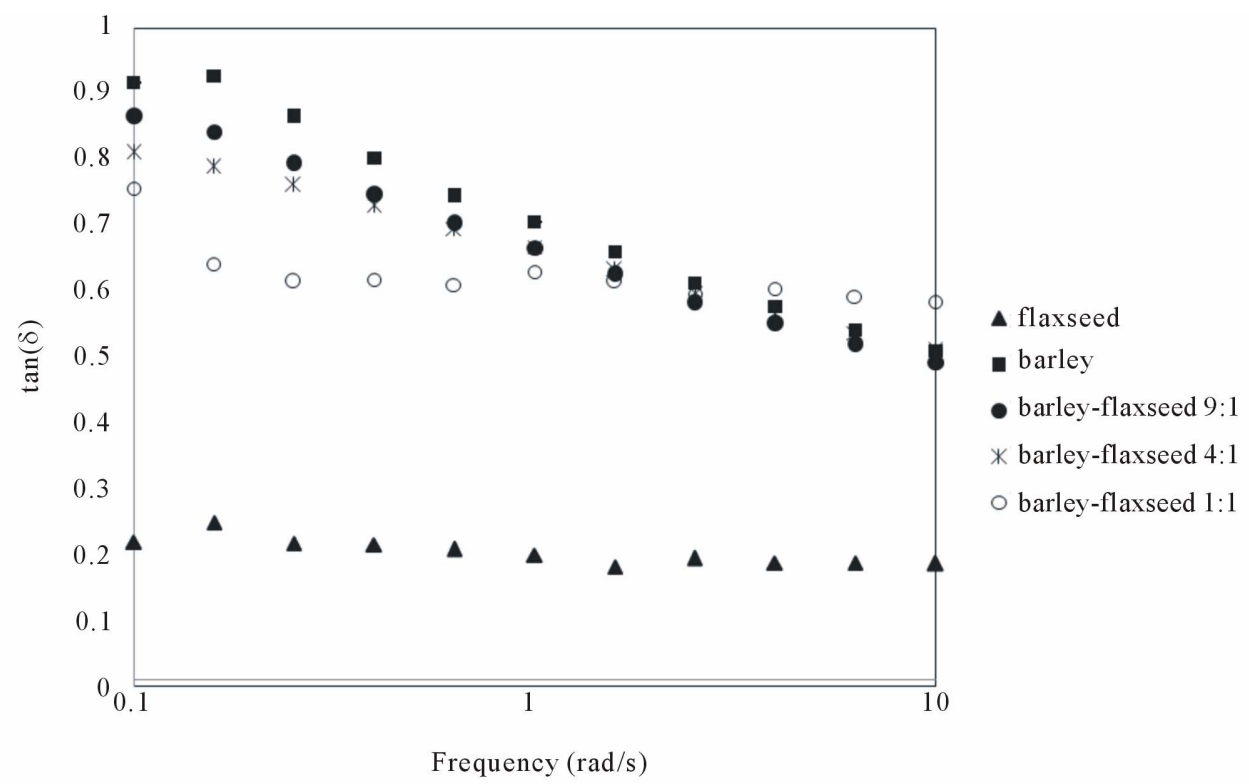

Figure 4. Values of $\tan (\delta)$ versus frequency $(\mathrm{rad} / \mathrm{s})$ for barley and its composites with flaxseed at $25^{\circ} \mathrm{C}$.

shear thinning behaviors over the entire measured shear rates at $25^{\circ} \mathrm{C}$ by exhibiting the flow behavior index $<1$ [34]. Shear-thinning behavior can be observed in many food materials such as soy, rice, and wheat flour [32]. This type of shear-thinning behavior is attributed to the disruption of random coil polymers and/or their parallel alignment with flow stream during shearing reported in the literature [35]. Barley-flaxseed 9:1 and 4:1 seems to have higher apparent viscosity, similar to barley flour, followed by barley-flaxseed 1:1, while flaxseed had a lower apparent viscosity than barley and all barley-flaxseed composites. Interestingly, barley-flaxseed 1:1 had slightly low apparent viscosity than flaxseed at the low shear rate, the apparent viscosities increased with increasing shear rate gradually, and were higher at high shear rate than flaxseed, indicating resistance to high shearing. It could be attributed to the interaction with the beta-glucan component in barley.

The shear apparent viscosities for all barley-flaxseed 9:1, 4:1 and 1:1 composites were improved by the barley component. The apparent viscosities suggested that those composites could have a similar thickening-effect to barley in food processing. The apparent viscosities were decreased by the increase of flaxseed contents showing shear-thinning behavior. Shear-thinning behavior of composites has several potential advantages in food 


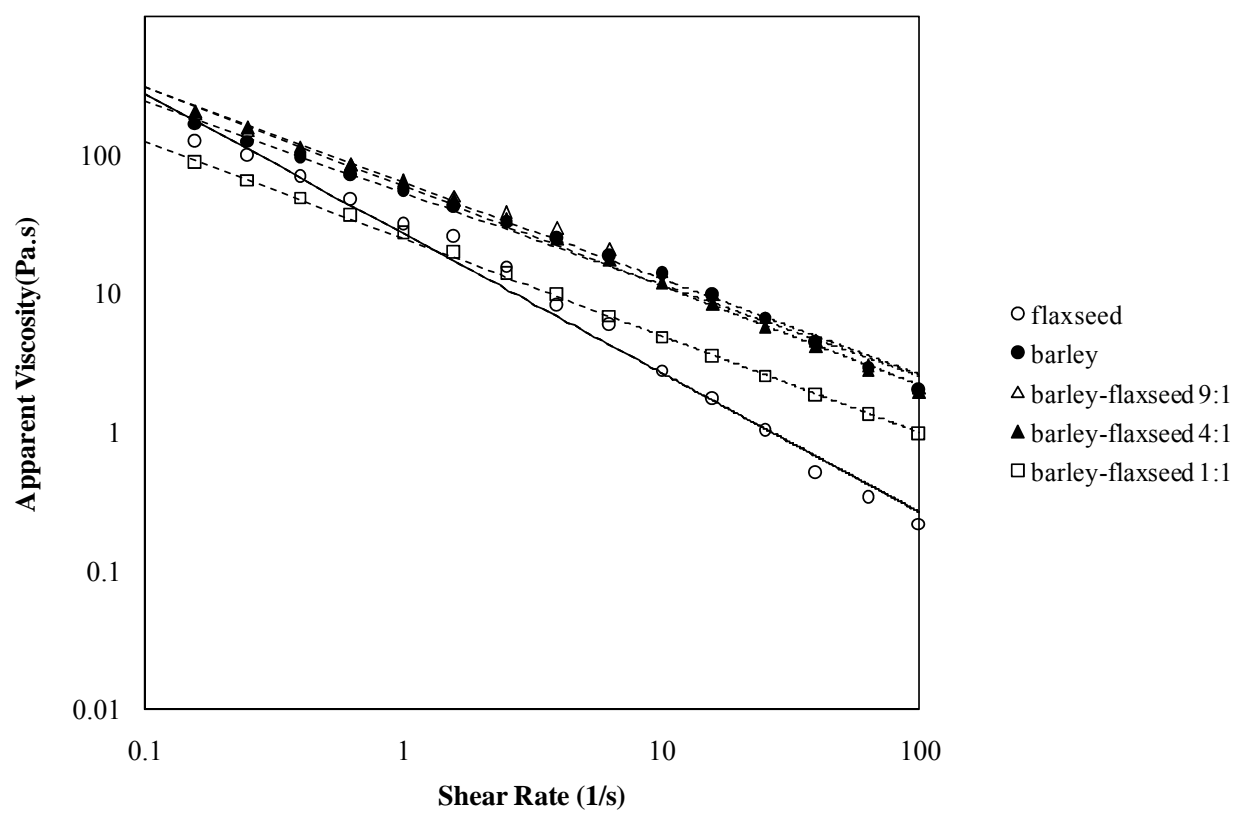

Figure 5. Apparent viscosity versus shear rate plots of barley and its composites with flaxseed at $25^{\circ} \mathrm{C}$.

Table 1. Magnitude of the powder-model parameters for flaxseed and its composites with barley.

\begin{tabular}{cccccc}
\hline & Flaxseed & Barley & Barley-flaxseed 9:1 & Barley-flaxseed 4:1 & Barley-flaxseed 1:1 \\
\hline $\mathrm{K}$ & 27.069 & 53.281 & 61.972 & 58.899 & 24.712 \\
$\mathrm{n}$ & -1.006 & -0.662 & -0.691 & -0.716 & -0.701 \\
$\mathrm{R}^{2}$ & 0.9881 & 0.9937 & 0.9972 & 0.9972 & 0.9985 \\
\hline
\end{tabular}

applications since viscosity was reduced with increasing shear rates. This behavior becomes favorable in many industrial operations such as mixing and pumping. In addition, it was reported that the polysaccharide solutions in which viscosity decreases rapidly at shear rates are easily and quickly swallowed during eating [36]. Hence, the shear-thinning behavior can impart a light and nonslimy mouthfeel to food products. Most food processing and mastication occur in a shear rate range of 0.1 to 100/sec [37]. Rheological properties of food products, specifically apparent viscosity, have been used as references for predicting their performance during processing [38]. Because the experimental conditions we adopted were similar to actual processing situations, all our findings on rheological characteristics could be beneficial for processing and developing flaxseed composites for functional food applications.

\section{Conclusion}

The pasting and rheological properties of barley-flaxseed composites revealed some interesting properties and useful information on their potential nutritional food applications. Flaxseed alone was not easily used in food products because of their small size with high oil content and low cohesiveness. Barley-flaxseed composites were unique because they provide the soluble fiber $\beta$-glucan that is beneficial for food texture and coronary heart disease prevention along with the health benefits of the $\omega-3$ PUFAs of flaxseed. The barley-flaxseed composites were created using a feasible dry blending procedure that could maintain the original barley flour quality along with the lipoidal character and components of the flaxseed. Besides the nutritional aspects of the barley-flaxseed composites, these composites have improved water holding capacities, texture, and useful viscoelastic qualities. These technologically developed products could be valuable for new functional foods having improved nutritional value and desirable texture qualities for health concerned consumers.

\section{REFERENCES}

[1] B. K. Baik and S. E. Ullrich, "Barley for Food: Characteristics, Improvement, and Renewed Interest," Journal of Cereal Science, Vol. 48, No. 2, 2008, pp. 233-242. doi:10.1016/j.jcs.2008.02.002

[2] T. Madhujith and F. Shahidi, "Antioxidative and Antiproliferative Properties of Selected Barley (Hordeum vulgarae L.) Cultivars and Their Potential for Inhibition of 
Low-Density Lipoprotein (LDL) Cholesterol Oxidation," Journal of Agricultural and Food Chemistry, Vol. 55, No. 13, 2007, pp. 5018-5024. doi:10.1021/jf070072a

[3] A. K. Holtekjølen, A. B. Bævre, M. Rødbotten, H. Berg and S. H. Knutsen, "Antioxidant Properties and Sensory Profiles of Breads Containing Barley Flour," Food Chemistry, Vol. 110, No. 2, 2008, pp. 414-421. doi:10.1016/j.foodchem.2008.02.054

[4] C. W. Newman and R. K. Newman, "A Brief History of Barley Foods," Cereal Food World, Vol. 51, 2006, pp. 4-7.

[5] E. A. Arndt, "Whole-Grain Barley for Today's Health and Wellness Needs," Cereal Foods World, Vol. 51, No. 1, 2006, pp. 20-22.

[6] S. W. Cui and Q. Wang, "Cell Wall Polysaccharides in Cereals: Chemical Structures and Functional Properties," Structural Chemistry, Vol. 20, No. 2, 2009, pp. 291-297. doi:10.1007/s11224-009-9441-0

[7] C. F. Klopfenstein, "The Role of Cereal Beta-Glucans in Nutrition and Health," Cereal Food World, Vol. 33, 1988, pp. 865-869.

[8] D. J. Rose, M. T. DeMeo, A. Keshavarzian and B. R. Hamaker, "Influence of Dietary Fiber on Inflammatory Bowel Disease and Colon Cancer: Importance of Fermentation Pattern," Nutrition Review, Vol. 65, No. 2, 2007, pp. 51-62. doi:10.1111/j.1753-4887.2007.tb00282.x

[9] S. Lee, G. E. Inglett and C. J. Carriere, "Effect of Nutrim Oat Bran and Flaxseed on Rheological Properties of Cakes," Cereal Chemistry, Vol. 81, No. 5, 2004, pp. 637642. doi:10.1094/CCHEM.2004.81.5.637

[10] C. M. Rosell, J. A. Rojas and C. Benedito de Barber, "Influence of Hydrocolloids on Dough Rheology and Bread Quality," Food Hydrocolloids, Vol. 15, No. 1, 2001, pp. 75-81. doi:10.1016/S0268-005X(00)00054-0

[11] J. A. Rojas, C. M. Rosell and C. Benedito de Barber, "Pasting Properties of Different Wheat Flour-Hydrocolloid Systems," Food Hydrocolloids, Vol. 13, No. 1, 1999, pp. 27-33. doi:10.1016/S0268-005X(98)00066-6

[12] S. Lee, K. Warner and G. E. Inglett, "Rheological Properties and Baking Performance of New Oat $\beta$-Glucan-Rich Hydrocolloids," Journal of Agricultural and Food Chemistry, Vol. 53, No. 25, 2005, pp. 9805-9809. doi:10.1021/jf0513680

[13] M. H. Lee, M. H. Baek, D. S. Cha, H. J. Park and S.T. Lim, "Freeze-Thaw Stabilization of Sweet Potato Starch Gel by Polysaccharide Gums," Food Hydrocolloids, Vol. 16, No. 4, 2002, pp. 345-352. doi:10.1016/S0268-005X(01)00107-2

[14] J. A. Gallegos-Infante, N. E. Rocha-Guzman, R. F. Gonzalez-Laredo and J. Pulido-Alonso, "Effect of Processing on the Antioxidant Properties of Extracts from Mexican Barley (Hordeum vulgare) Cultivar," Food Chemistry, Vol. 119, No. 3, 2010, pp. 903-906. doi:10.1016/j.foodchem.2009.07.044

[15] V. Verardo, M. Bonoli, E. Marconi and M. F. Caboni, "Distribution of Bound Hydroxycinnamic Acids and Their Glycosyl Esters in Barley (Hordeum vulgare L.) Air-Classified Flour: Comparative Study between Re- versed Phase-High Performance Chromatography-Mass Spectrometry (RP-HPLC/MS) and Spectrophotometric Analysis," Journal of Agricultural and Food Chemistry, Vol. 56, No. 24, 2008, pp. 11900-11905. doi:10.1021/jf802260e

[16] V. Verardo, M. Bonoli, E. Marconi and M. F. Caboni, "Determination of Free Flavan-3-ol Content in Barley (Hordeum vulgare L.) Air-Classified Flours: Comparative Study of HPLC-DAD/MS and Spectrophotometric Determinations," Journal of Agricultural and Food Chemistry, Vol. 56, No. 16, 2008, pp. 6944-6948. doi:10.1021/jf8006344

[17] G. E. Inglett, D. Chen and M. Berhow, "Influence of Jet Cooking Prowashonupana Barley Flour on Phenolic Composition, Antioxidant Activities, and Viscoelastic Propetrties," Cereal Chemistry, Vol. 88, No. 3, 2011, pp. 315-320. doi:10.1094/CCHEM-10-10-0150

[18] V. Juturu, "Omega-3 Fatty Acids and the Cardiometabolic Syndrome," Journal of the Cardio Metabolic Syndrome, Vol. 3, No. 4, 2008, pp. 244-253. doi:10.1111/j.1559-4572.2008.00015.x

[19] P. M. Kris-Etherton, W. S. Harris and L. J. Appel, "Fish Consumption, Fish Oil, Omega-3 Fatty Acids, and Cardiovascular Disease," Circulation, Vol. 106, 2002, pp. 2747-2757. doi:10.1161/01.CIR.0000038493.65177.94

[20] G. Zhao, T. D. Etherton, K. R. Martin, P. J. Gillies, S. G. West and P. M. and Kris-Etherton, "Dietary a-Linolenic Acid Inhibits Proinflammatory Cytokine Production by Peripheral Blood Mononuclear Cells in Hypercholesterolemic Subjects," The American Journal of Clinical Nutrition, Vol. 85, 2007, pp. 385-391.

[21] Food and Drug Administration, 2004. www.fda.gov/SiteIndex/ucm108341.htm

[22] E. Reyes-Caudillo, A.Tecante and M. A. Valdivia-López, "Dietary Fibre Content and Antioxidant Activity of Phenolic Compounds Present in Mexican Chia (Salvia hispanica L.) Seeds," Food Chemistry, Vol. 107, No. 2, 2008, pp. 656- 663. doi:10.1016/j.foodchem.2007.08.062

[23] J. N. BeMiller, "Quince Seed, Psyllium Seed, Flaxseed and Okra Gums," In: R. S. Whistler and J. N. Bemiller, Eds., Industrial Gums, 2nd Edition, Academic Press, New York, 1973, pp. 331-337.

[24] G. Mazza and C. G. Biliaderis, "Functional Properties of Flaxseed Mucilage," Journal of Food Science, Vol. 54, No. 5, 1989, pp. 1302-1305. doi:10.1111/j.1365-2621.1989.tb05978.x

[25] G. Muralikrishna, P. V. Salimath and R. N. Tharanathan, "Structural Features of an Arabinoxylan and a Rhamnogalactouronan Derived from Linseed Mucilage," Carbohydrate Research, Vol. 161, 1987, pp. 265-271.

[26] K. Wannerberger, T. Nylander and M. Nyman, "Rheological and Chemical Properties of Mucilage in Different Varieties from Linseed (Linum usitatissimum)," Acta Agriculturae Scandinavica, Vol. 41, No. 3, 1991, pp. 311319. doi:10.1080/00015129109439914

[27] W. Cui, G. Mazza, B. D. Oomah and C. G. Biliaderis, "Optimization of an Aqueous Extraction Process of Flaxseed Gum by Response Surface Methodology," LWT- 
Food Science and Technology, Vol. 27, No. 4, 1994, pp. 363-369. doi:10.1006/fstl.1994.1074

[28] B. I. O. Ade-Omowaye, K. A. Taiwo, N. M. Eshtiaghi, A. Angersbach and D. Knorr, "Comparative Evaluation of the Effects of Pulsed Electric Field and Freezing on Cell Membrane Permeabilisation and Mass Transfer during Dehydration of Red Bell Peppers," Innovative Food Science \& Emerging Technologies, Vol. 4, No. 2, 2003, pp. 177-188. doi:10.1016/S1466-8564(03)00020-1

[29] SAS Institute Inc., "The SAS ${ }^{\circledR}$ System for Windows ${ }^{\circledR}$," Version 8e, Cary, 1999.

[30] S. Lee, G. E. Inglett, D. Palmquist and K. Warner, "Flavor and Texture Attributes of Foods Containing-GlucanRich Hydrocolloids from Oats," LWT-Food Science and Technology, Vol. 42, 2009, pp. 350-357.

[31] L. S. Lai and C. L. Liao, "Steady and Dynamic Shear Rheological Properties of Starch and Decolorized HsianTsao Leaf Gum Composite Systems," Cereal Chemistry, Vol. 79, No. 1, 2002, pp. 58-63. doi:10.1094/CCHEM.2002.79.1.58

[32] S. Lee and G. E. Inglett, "Rheological and Physical Evaluation of Jet-Cooked Oat Bran in Calorie Cookies" International Journal of Food Science and Technology, Vol. 41, No. 5, 2006, pp. 553-559. doi:10.1111/j.1365-2621.2005.01105.x

[33] N. G. Gravier, N. E. Zaritzky and A. N. Califano, "Viscoelastic Behavior of Refrigerated and Frozen LowMoisture Mozzarella Cheese," Journal of Food Science, Vol. 9, No. 3, 2004, pp. 123-128.

[34] S. Lee and G. E. Inglett, "Effect of an Oat Beta-GlucanRich Hydrocolloid (C-trim30) on the Rheology and Oil Uptake of Frying Batters," Journal of Food Science, Vol. 72, No. 4, 2007, pp. E222-E226. doi:10.1111/j.1750-3841.2007.00326.x

[35] J. C. Salamone, "Polymeric Materials Encyclopedia," CRC Press, Boca Raton, 1996.

[36] A. S. Szczesniak and E. Farkas, "Objective Characterization of the Mouthfeel of Gum Solutions," Journal of Food Science, Vol. 27, No. 4, 1962, pp. 381-385. doi:10.1111/j.1365-2621.1962.tb00112.x

[37] A. Bloksma, "Rheology of the Bread Making Process," 8th International Cereal and Bread Congress, Lausanne, 30 May-3 June 1998.

[38] A. Salvador, T. Sanz and S. Fiszman, "Effect of Corn Flour, Salt, and Leavening on the Texture of Fried, Battered Squid Rings," Journal of Food Science, Vol. 67, No. 2, 2002, pp. 730-733. doi:10.1111/j.1365-2621.2002.tb10667.x 